\title{
Success Factors of Adapting Agile Methods in Global and Local Software Development: A Systematic Literature Review Protocol with Preliminary Results
}

\author{
Irfan Ullah \\ Department of Computer \\ Sciences and Software \\ Engineering, University \\ of Engineering \& \\ Technology, KPK, \\ Pakistan
}

\author{
Ibrar Ali Shah, PhD \\ Department of Computer \\ Sciences and Software \\ Engineering, University \\ of Engineering \& \\ Technology, KPK, \\ Pakistan
}

\author{
Fawad Ghafoor \\ Department of Computer \\ Sciences and Software \\ Technology, University of \\ Swat, KPK, Pakistan
}

\author{
Rehan Ullah Khan \\ Department of Computer \\ Sciences and Software \\ Technology, University of \\ Swat, KPK, Pakistan
}

\begin{abstract}
Agile methodologies are used for developing software both in local software development (LSD) and global software development (GSD) companies because it provides extensive benefits like proper communication, customer satisfaction, close collaboration, and frequent delivery of working software etc. to these developments [1]. In this paper, Systematic Literature Review (SLR) protocol is constructed to know about the success factors of implementing agile methodologies in LSD as well as in GSD. The result of this SLR protocol is a group of success factors which are very helpful for local and global software companies to know about importance of agile methodologies. The result of SLR protocol is also presented in this paper.
\end{abstract}

\section{Keywords}

Agile Software Development (ASD), Local Software Development (LSD), Global Software Development (GSD), Agile Local Software Development (ALSD, Agile Global Software Development (AGSD), Systematic Literature Review (SLR).

\section{INTRODUCTION}

Agile Software Development (ASD) is a combination of methodologies for software developments, based on iterative and incremental developments, where requirements are obtained through collaboration between customers and developers [2]. The aim of agile software development is to make development processes which are lighter, quick and more responsive to change. Agile methodology is being used for high-speed, volatile world of Internet and Web application developments [3]. Agile methodology provides software's main version in short iterations and then updates it according to the need of the requirements of customer. This method of software development is best for overcoming frequent changes and to deliver the working software very fast along with the satisfaction of customer [2]

The term Local Software Development (LSD) refers to software development in local software companies where software developers located at the same areas like provinces, districts, and cities within same country [4]. Agile methods used in LSD are referred as Agile Local Software Developments (ALSD). There are many benefits of implementing agile in LSD, which are Risk Management, Improved Communication, Increased Productivity, Increased Quality, Building Trust, Early Detection of Problems, Iterative Development, Cost Reduction, High Visibility,
Change Management, Training, Reduced Development Time, Self-Organizing Teams, and Availability of Tools \& Technology, Strong Collaboration covered in this thesis in detail.

The term Global Software Development (GSD) refers to software developments where software developers are located at various parts of the globe [4]. These developers develop software commercially for earning money and work for software companies, which are outside of their countries. Software companies seeking lower costs and skilled developers of other countries to work for their companies [5]. Distribution of software development is becoming practice that is more common because it reduces cost and time to market. There are many benefits including access to large pool of developers, cost advantage and round-the-clock development [2]. Agile used in GSD is referred as Agile Global Software Developments (AGSD). There are many benefits of implementing agile in GSD, which are Improved Communication, Improved Trust, Improved Coordination, Improved Transparency, Improved Motivation, Improved Quality, Improved Collaboration, Early Identification of Problems, Customer Availability, Customer Satisfaction, Flexibility, Rapid Development Time, Availability of Tools, Improved Integration, Improved Processes, Frequent Build, and Short Iteration covered in this research in detail.

This paper tries to answer the following research questions:

Q1: What are the success factors, as identified in the literature, in adapting agile methods in LSD?

Q2: What are the success factors, as identified in the literature, in adapting agile methods in GSD?

\section{BACKGROUND}

According to [6], the agile is lightweight methodology which becomes very popular and attracted attention of software engineering community from last few years. This methodology has short iteration cycles which are opposite to traditional methods which as a lot of documentations. It presents the effectiveness of using agile in software industry. Author of this paper make questionnaire and distribute it to software industries to get feedback for comparing agile methodology with traditional methodologies. On the basis of this comparison he found that agile methodologies are very beneficial for small and medium scaled projects, how according to this paper, there are very few benefits in large scaled projects. 
In [7], the authors present the lesson, after studying 12 case studies related to successful implementation of agile in distributed software developments. He analyzed these case studies based on principles of agile manifesto. This paper discovered the solutions used by different companies for overcoming challenges of distributed agile software development.

In [8], advantages and success factors for implementing agile methodologies in Small companies are presented. The author applied Agile Framework for Small Projects (AFSP) to 4 industries and then evaluates their results. He analyzed the case studies on the basis of risk-based agility factors, level of agile implementation, and the degree of success of agile project. The result of this paper shows that agile is very effective when implemented in small projects.

In [9], the result of implementing agile methodology in university environment is described. This paper is divided into three sections: 1. Overview of Scrum--agile methodology is presented. 2. Way of using Scrum during the development of Student Record Information System (SRIS) at the University of Ljubljana. 3. Advantages of using Scrum.

In [10], the advantages of using agile in distributed environments are presented. According to this paper, challenges faced by distributed environments like "time and cultural differences" and "geographical distances" are overcome by implementation of agile methodologies. By using agile methodologies, communication between the team is very strong, effective, and efficient. This paper discusses both formal and informal methods of communication along with its pros and cons, when applying agile practices in GSD.

According to [11], temporal, geographical and socio-cultural distances which are faced by GSD are decreased by using agile. It present one of the most powerful and famous agile methodology called Scrum is used for mitigating challenges faced by GSD. This paper is useful for practitioners who are seeking to understand the effectiveness of Scrum in GSD, and for researchers to validate current knowledge.

According to [12], there are various factors faced by GSD like time and distance differences, mismatch between team and cultural behaviors which leads to collaboration and communication challenges. These challenges are overcome by adopting agile practices in GSD.

In [13], several GSD challenges are reviewed and then available agile practices are reviewed for mitigation of these challenges. Scrum is one of the best agile methodologies and it is very best since its use in GSD setting. This paper is specially recommended to GSD developers and agile practitioners for recognition of agile remedies to reduce GSD challenges.

In [14], the authors discuss the usefulness of published research on agile in GSD for practitioner. For this paper, they used XP - an agile methodology conferences between 2001 and 2005. This paper is also very useful for research in this field in the future.

In [15], the authors present that agile methodology is very beneficial when applied to GSD for mitigating communication related challenges. According to this paper, agile methodologies are applied in those cases where regular face-to-face communication is impossible. In this paper, the author also described usefulness of agile implementations in globally distributed student projects, for developing industrial client's software.
In [16], the author describes the advantages of using Scrum and agile processes in distributed software development. $\mathrm{He}$ also proposes two team structures for its implementation. Advantages of agile presented in this paper are: improved communication, security, collaboration, integration, efficiency, iterative development, and availability of tools.

\section{RESEARCH METHODOLGY}

This research uses Systematic Literature Review (SLR) for finding advantages and success factors of agile in GSD \& LSD. In this method, multiple research papers are collected and then critically analyzed for obtaining required data $[17$, 18]. It is a specified and systematic method for identifying and analyzing published research papers of the same field to answer a specific research question. This method is different from other ordinary literature review as it is being planned and systematically executed. Result produced through this method is highly valid and useful that might be not possible in other methods [18].

Following are the major steps in SLR:

1. Constructing the search strings, then performing search using specific search engines to find relevant studies.

2. Performing the selection process for proposed study.

3. Apply study quality assessment.

4. Extracting the required data.

5. Synthesis of the extracted data.

\section{SEARCH STRAGTEGY}

Search strategy is a method used for discussing the strategy, followed for searching the required primary sources. It is used for identification and collection of all the literature that are satisfied by criteria of inclusion and exclusion. In this section complete list of search engines and search strings which are used for searching are presented.

\subsection{Search Engines}

Following search engines are searched for identification and downloading the required primary sources.

1. Google Scholar: http://scholar.google.com/

2. ACM: http://www.acm.org/

3. IEEEXplore: $\mathrm{http}: / /$ ieeexplore.ieee.org/

4. Science Direct: http://www.sciencedirect.com/

5. Wiley interScience: http://interscience.wiley.com/

\subsection{Search Strings}

Following search strings has been used for searching through above search engines.

('Agile' OR 'Agile methods' OR 'Agile Software Development') AND ('Global Software Development' OR 'GSD' OR 'Distributed Software Development') AND ('Local Software Development' OR 'LSD') AND ('Success Factors' OR ‘Advantages' OR 'Motivations')

\section{SELECTION CRITERIA}

This section presents the inclusion and exclusion criteria which are used to ensure that only specified primary sources are selected. Paper selection process is also discussed in this section. -

\subsection{Inclusion Criteria}

Following inclusion criteria is used for considering the most suitable and relevant papers. 
1. Only those papers will be considered which are written in English language.

2. Only those papers will be considered which discusses success factors/benefits/advantages of Agile in GSD.

3. Only those papers will be considered which discusses success factors/benefits/advantages of Agile in LSD.

4. Only those papers will be considered which discusses success factors/benefits/advantages of Agile methodologies in GSD.

5. Only those papers will be considered which discusses success factors/benefits/advantages of Agile methodologies in LSD.

\subsection{Exclusion Criteria}

Following exclusion criteria is used for excluding the irrelevant papers.

1. Paper(s) will be excluded if it not relevant to research questions.

2. Paper(s) will be excluded if not discusses Agile or its methodologies.

3. Paper(s) will be excluded if not discusses Agile with respect to GSD.

4. Paper(s) will be excluded if not discusses Agile with respect to LSD.

\subsection{Selection Process}

This section shows the two phases which are followed for selection processes.

1. Primary sources were selected on the basis of paper's title and abstract. On the basis of this phase, 84 primary sources/papers were selected.

2. Selected primary sources/papers were then reviewed critically according to selection criteria for extracting more relevant and suitable papers. On the basis of this phase, 51 papers were selected for extraction of data.

\section{DATA EXTRACTIONS}

In this section, the data has been extracted from final selected publications, using the data extraction form, as depicted in Table 1.

Table 1: Data Extraction Form

\begin{tabular}{|l|l|}
\hline S. No & Data to be extracted \\
\hline 1 & Date of Review \\
\hline 2 & Title of the Paper \\
\hline 3 & Country of the Author \\
\hline 4 & Study Strategy \\
\hline 5 & Agile Methodology \\
\hline 6 & Company Scope (Local, Global) \\
\hline 7 & $\begin{array}{l}\text { Success Factors/benefits/advantages of } \\
\text { Agile Methodologies in GSD }\end{array}$ \\
\hline 8 & $\begin{array}{l}\text { Success Factors/benefits/advantages of } \\
\text { Agile Methodologies in LSD }\end{array}$ \\
\hline
\end{tabular}

\section{DATA SYNTHESIS}

In this phase of research, the success factors which are extracted in Section-6 were combined into two groups as shown in Table 2 and Table 3, for finding the number of frequency and percentage of each paper.

Table 2: Data Synthesis of "Success Factors of Agile in GSD"

\begin{tabular}{|l|l|l|c|c|}
\hline $\begin{array}{l}\text { S. } \\
\text { No }\end{array}$ & $\begin{array}{l}\text { Success } \\
\text { Factors }\end{array}$ & Paper Id & Frequency & Percentage \\
N = 27
\end{tabular}


Table 3: Data Synthesis of "Success Factors of Agile in LSD"

\begin{tabular}{|c|c|c|c|c|}
\hline $\begin{array}{l}\text { S. } \\
\text { No }\end{array}$ & $\begin{array}{l}\text { Success } \\
\text { Factors }\end{array}$ & Paper Id & Frequency & $\begin{array}{l}\text { Percentage } \\
\mathrm{N}=\mathbf{2 4}\end{array}$ \\
\hline 1 & $\begin{array}{l}\text { Risk } \\
\text { Management }\end{array}$ & $\begin{array}{l}\text { S26,S32,S37, } \\
\text { S58 }\end{array}$ & 4 & $17 \%$ \\
\hline 2 & $\begin{array}{l}\text { Improved } \\
\text { Communication }\end{array}$ & $\begin{array}{l}\text { S9,S22,S26, } \\
\text { S31,S34,S35, } \\
\text { S37,S42,S43, } \\
\text { S45,S54,S60 }\end{array}$ & 12 & $50 \%$ \\
\hline 3 & $\begin{array}{l}\text { Increased } \\
\text { Productivity }\end{array}$ & $\begin{array}{l}\text { S8,S32,S35, } \\
\text { S38 }\end{array}$ & 4 & $17 \%$ \\
\hline 4 & $\begin{array}{l}\text { Increased } \\
\text { Quality }\end{array}$ & $\begin{array}{l}\text { S8,S21,S31, } \\
\text { S32,S34,S37, } \\
\text { S38,S49 }\end{array}$ & 8 & $33 \%$ \\
\hline 5 & Building Trust & S9,S45,S52 & 3 & $12 \%$ \\
\hline 6 & $\begin{array}{l}\text { Early Detection } \\
\text { of Problems }\end{array}$ & S9,S16,S21 & 3 & $12 \%$ \\
\hline 7 & $\begin{array}{l}\text { Iterative } \\
\text { Development }\end{array}$ & $\begin{array}{l}\text { S16,S31,S35, } \\
\text { S44, }\end{array}$ & 4 & $17 \%$ \\
\hline 8 & Cost Reduction & $\begin{array}{l}\text { S21,S35,S38, } \\
\text { S49 }\end{array}$ & 4 & $17 \%$ \\
\hline 9 & High Visibility & $\begin{array}{l}\text { S9,S21,S38, } \\
\text { S60 }\end{array}$ & 4 & $17 \%$ \\
\hline 10 & $\begin{array}{l}\text { Change } \\
\text { Management }\end{array}$ & $\begin{array}{l}\mathrm{S} 26, \mathrm{~S} 31, \mathrm{~S} 32, \\
\mathrm{~S} 34, \mathrm{~S} 35, \mathrm{~S} 36, \\
\mathrm{~S} 37, \mathrm{~S} 44, \mathrm{~S} 49\end{array}$ & 9 & $37 \%$ \\
\hline 11 & Training & $\begin{array}{l}\mathrm{S} 1, \mathrm{~S} 23, \mathrm{~S} 26, \\
\mathrm{~S} 31, \mathrm{~S} 36, \mathrm{~S} 43\end{array}$ & 6 & $25 \%$ \\
\hline 12 & $\begin{array}{l}\text { Reduced } \\
\text { Development } \\
\text { Time }\end{array}$ & $\begin{array}{l}\text { S9,S21,S22, } \\
\text { S31,S32,S35, } \\
\text { S49,S60 }\end{array}$ & 8 & $33 \%$ \\
\hline 13 & $\begin{array}{l}\text { Self-Organizing } \\
\text { Teams }\end{array}$ & $\begin{array}{l}\mathrm{S} 22, \mathrm{~S} 26, \mathrm{~S} 32, \\
\mathrm{~S} 36, \mathrm{~S} 42, \mathrm{~S} 43\end{array}$ & 7 & $29 \%$ \\
\hline 14 & $\begin{array}{l}\text { Availability of } \\
\text { Tools \& } \\
\text { Technology }\end{array}$ & $\begin{array}{l}\text { S23,S44,S52, } \\
\text { S54 }\end{array}$ & 4 & $17 \%$ \\
\hline 15 & $\begin{array}{l}\text { Strong } \\
\text { Collaboration }\end{array}$ & $\begin{array}{l}\mathrm{S} 22, \mathrm{~S} 31, \mathrm{~S} 35, \\
\mathrm{~S} 42, \mathrm{~S} 44, \mathrm{~S} 52\end{array}$ & 6 & $25 \%$ \\
\hline
\end{tabular}

\section{CONCLUSION}

In this paper, SLR protocol is presented for identification of success factors while adapting agile methods in GSD \& LSD.

Preliminary result (success factors of agile methodologies in GSD and LSD) are also presented in this paper. Agile methodologies are applied to both Global and Local software companies and there are lots of advantages, success factors or benefits of it. In this paper SLR protocol is executed to highlight these success factors. Using a designed search strings on search engines, $\mathrm{N}=84$ papers were founded which after selection criteria in Section-5 reduced to $\mathrm{N}=51$, among which $\mathrm{N}=24$ belongs to LSD and $\mathrm{N}=27$ to GSD. Finally, table-2 \& table-3 presents these success factors when implementing Agile methodologies in GSD and LSD respectively along with their frequencies and percentages.

This research is best for researchers and practitioners for knowing complete list of advantages using ASD in GSD as well as in LSD. Software companies can implement their best practices after knowing the complete list of success factors discussed in this paper.

This study can be extended by comparison of success factors and issues/challenges in AGSD \& ALSD.

\section{REFERENCES}

[1] Level, I., Tutorial, A., Dates, 2., Tests, I., Us, C., \& Policy, P. et al. (2017). What is Agile model advantages, disadvantages and when to use it?. Istqbexamcertification.com. Retrieved from http://istqbexamcertification.com/what-is-agile-modeladvantages-disadvantages-and-when-to-use-it/ last accessed 8 March 2017.

[2] Shrivastava, Suprika Vasudeva. "Distributed agile software development: A review." arXiv preprint arXiv:1006.1955 (2010)

[3] Paulk, Mark C. "Agile methodologies and process discipline." Institute for Software Research (2002):3

[4] Ghafoor, Fawad, Ibrar Ali Shah, and Nasir Rashid. "Issues in Adopting Agile Methodologies in Global and Local Software Development: A Systematic Literature Review Protocol with Preliminary Results." International Journal of Computer Applications 160.7 (2017).

[5] Herbsleb, James D., and DeependraMoitra. "Global software development."Software, IEEE 18.2 (2001): 1620 .

[6] Awad, M. A. "A comparison between agile and traditional software development methodologies." University of Western Australia (2005).

[7] Bose, Indranil. "Lessons Learned From Distributed Agile Software Projects: A Case Based Analysis." Communications of the Association for Information Systems (2008).

[8] Lee, Seiyoung, and Hwan-Seung Yong. "Agile software development framework in a small project environment." Journal of Information Processing Systems 9.1 (2013): 69-88.

[9] Mahnic, Viljan, and SlavkoDrnovscek. "Agile software project management with scrum." EUNIS 2005 Conference-Session papers and tutorial abstracts. 2005.

[10] Bhatnagar, Karishma. "Collaboration and Communication in Agile Global Software Development."

[11] Hossain, Emam, Paul L. Bannerman, and D. Ross Jeffery. "Scrum practices in global software development: a research framework." International Conference on Product Focused Software Process Improvement. Springer Berlin Heidelberg, 2011

[12] Global Prospect of Distributed Agile Software Development: A Review. Retrieved from http://www.seekdl.org/nm.php?id=1336\%E2\%80\%8E last accessed 14 April 2017 
[13] Agile Development Overcomes GSD Challenges: A Systematic Literature Review. Retrieved from http://ijcsse.org/published/volume6/issue1/p2-V6I1.pdf Last accessed 14 April 2017.

[14] Taylor, Philip S., et al. "Do agile GSD experience reports help the practitioner?" Proceedings of the 2006 international workshop on Global software development for the practitioner. ACM, 2006.

[15] Paasivaara, Maria, and Casper Lassenius. "Could global software development benefit from agile methods?" Global Software Engineering, 2006. ICGSE'06. International Conference on. IEEE, 2006.
[16] Phalnikar, Rashmi, V. S. Deshpande, and S. D. Joshi. "Applying agile principles for distributed software development." Advanced Computer Control, 2009. ICACC'09. International Conference on. IEEE, 2009.

[17] C. Okoli and K. Schabram, "A guide to conducting a systematic literature review of information systems research," 2010.

[18] S. Keele, "Guidelines for performing systematic literature reviews in software engineering," Technical report, EBSE Technical Report EBSE-2007-01 2007. 